\title{
O pensamento plural e sistêmico diante as necessidades no mundo contemporâneo
}

\author{
DOI: http://dx.doi.org/10.20435/multi.v24i57.2646
}

O fato de o pensamento ser naturalmente plural e sistêmico não significa que toda pluralidade deve ser aceita, visto que existem pensamentos nefastos, criminosos, doentios e tanáticos. Prova disso são as atitudes advindas do sectarismo tão presente na atualidade e que tem resultado na degradação da vida humana expressa pelas mais distintas maneiras, inclusive com atos de terrorismo. Tal sectarismo, inclusive o de natureza religiosa e política, tem resultado na atualidade em profundo desrespeito no que tange à vida em sua plenitude, particularmente a vida humana.

Não obstante a necessidade de se respeitar o pensamento distinto, é preocupante a máxima de que todos podem falar o que bem lhe aprouver, visto que isso tem servido para a "domesticação" e "lavagem cerebral" a serviço de interesses espúrios, ou seja, o sagrado direito de discordar tem servido para apregoar mentiras [fake news] dos mais distintos matizes. A rigor essas atitudes confrontam o que estabelece o Art. XIX da Declaração do Direitos Humanos, que estabelece:

Todo ser humano tem direito à liberdade de opinião e de expressão; este direito inclui liberdade de, sem interferência, ter opiniões e de procurar, receber e transmitir informações e ideias por quaisquer meios e independente de fronteiras. (ONU, 1948).

Em outros termos, uma fake news representa a negação do direito de expressão, visto que apregoar mentiras resulta em prejuízos que atingem a formação correta de opinião da massa populacional e, em última instância, ferem o direito fundamental de informação, enquanto necessidade personalíssima.

Aqui não se advoga a necessidade de convergência de pensamento sobre todas as coisas, é obvio, mesmo porque isso é impossível em todas as dimensões da vida humana, indo desde as ideologias, filosofias e religiões até os conhecimentos científicos. 
Em vista do acima exposto, pode-se dizer que a dignidade da pessoa humana pode então ser um balizamento, um parâmetro para a justificação de restrições à veiculação de conteúdos nos meios de comunicação. Contudo esse balizamento não pode ser levado ao extremo, em especial, pelo fato de o conceito ser geral e abstrato, ser disputado por várias "ontologias, mundividências e concepções do bem", e por se tratar de conceito temporal, local e contextual. Por esses motivos, a sua aplicação para restringir a liberdade de expressão deve estar acompanhada de um "rigoroso controle material e procedimental" para não "assumir a natureza de uma imposição coerciva unilateral de uma dessas concepções a todos os cidadãos" (MACHADO, 2002 apud NAPOLITANO, 2017, p. 363).

O pensamento plural e sistêmico implica aceitar a diversidade de concepções, o que não pode ser admitido é o sectarismo a partir de posicionamentos individuais ou grupais, que em nada ajuda o mundo em sua dinâmica, particularmente voltada para propiciar avanços na compreensão da vida. Pensar de modo plural e sistêmico implica a dimensão científica e filosófica em aceitar a possibilidade do engano e avançar rumo à elucidação dos entraves epistemológicos e metodológicos.

Em vista dessas concepções, o número atual da Multitemas traz quinze trabalhos de acurado teor científico, cuja leitura, sem dúvida, poderá facilitar a compreensão do que se trata de fato o pensamento plural. Suas abordagens estão comprometidas com a construção de um mundo verdadeiramente sustentável, qual seja, com a perspectiva de garantia da vida futura, compreendo: 1) Estratégia para destinação de resíduos sólidos recicláveis provenientes de universidades brasileiras; 2) Avaliação do conhecimento e conduta dos acadêmicos da área da saúde sobre o uso de medicamentos; 3) Museus e escolas: parceria na efetivação de ações culturais para a formação de público consumidor de cultura; 4) Satisfação no trabalho e qualidade de vida de professores universitários brasileiros: revisão integrativa; 5) Compostos bioativos de geleia de bocaiuva acrescida de maracujá; 6) Aspectos jurídicos do bairro rural Portal da Lagoa de Campo Grande, MS, na perspectiva do Desenvolvimento Local; 7) A privatização do espaço e suas implicações desde a produção do espaço de Henri Lefebvre; 8) Uso de agrotóxicos e perfil de intoxicação humana na região Centro-Oeste 
do Brasil; 9) Consumo de alimentos e hábitos de vida de uma amostra de idosos de Campo Grande, MS; 10) O Programa de Estágio Docente (PED) como estratégia de formação: relato de experiência; 11) Efeitos da equoterapia na qualidade de vida de adolescente com TDHA; 12) Água como bem econômico: dessalinização para o combate da escassez hídrica no agronegócio; 13) Les fondements métaphysiques des cosmo-théosophies africaines: une lecture à partir des textes [Os fundamentos metafísicos das cosmo-teosofias africanas: uma leitura dos textos]; 14) Prevalência de Aleitamento Materno em Campo Grande, Mato Grosso do Sul, Brasil e 15) Por que os pais humanos merecem o Dia dos Pais.

Particularmente preocupante nesse contexto de sustentabilidade, qualidade de vida e pensamento plural e sistêmico é o que defende Sato et al. (2015) quando afirma que o planeta vem enfrentando muitos problemas, em consequência do crescente número de população que usa as alternativas oferecidas de maneira desordenada; e dentre as preocupações, tem-se como uma das principais, a destinação final dos resíduos sólidos que são despejados em sua maioria no meio ambiente agredindo solos, rios e ar. Os resíduos sólidos podem ser classificados de acordo com sua origem, tipo de resíduo, composição química e periculosidade. Um exemplo de tipos de origem são os resíduos domiciliares em que podem ser encontrados: restos de alimentos, resíduos sanitários, papel, plástico, vidro etc.

No tocante ao trabalho sobre o conhecimento e conduta dos acadêmicos da área da saúde, os resultados mostraram que $92,5 \%$ dos entrevistados possuem medicamentos em casa, como analgésicos, antitérmicos e anti-inflamatórios, e os compram sem orientação médica. Cerca de 72,5\% leem a bula do medicamento e conhecem os efeitos adversos. Em relação a isso, Lopes e Mata (2017) afirmam que a prevalência e a frequência dessa conduta entre acadêmicos decorrem da interferência da área de formação na qual estão inseridos, sendo os estudantes da área da saúde os que mais se automedicam. Isso se dá pelo fato de os acadêmicos dessa área terem maior conhecimento técnico acerca dos fármacos.

Pensar na satisfação no trabalho e qualidade de vida de professores universitários brasileiros implica pensar a universidade do ponto de vista de uma comunicação sistêmica, o que nos remete ao pensamento de 
Romero-Rodriguez e Castilho-Abdul (2019, p. 45) que afirmam:

Desde la perspectiva sistémica, la naturaleza relacional de la sociedad se manifiesta fundamentalmente en sus intercambios comunicativos, tanto en qué comunicamos, cómo lo hacemos y de qué manera. A esta capacidad, competencia o aptitud se le denomina 'habilidad social', que forma parte de la conducta adaptativa de cada sujeto (PinazoHernandis, 2006). Así se podría entender que la habilidad social es una capacidad instersubjetiva para usar recursos personales, conductuales, afectivos, cognitivos y culturales para lograr 'conectar' con nuestros interlocutores, pero que lejos de ser un rasgo de personalidad, es un comportamiento adquirido - y por ello, adaptativo - que coadyuva al individuo a desenvolverse mejor con su entorno social.

Como se pode ver, os demais assuntos abordados estão vinculados direta ou indiretamente com as condições e melhorias de vida da população, refletindo a preocupação de seus autores com a vida futura, mediante a satisfação das necessidades básicas e fundamentais do ser humano. Isso vem ao encontro do que pensam Mazzi, Marques e Ripoll (2019, p. 112-3) quando afirmam que, ao consideramos a relevância do trabalho na vida das pessoas, em especial, ao que se refere a influência que este exerce e representa em relação à motivação e à satisfação pessoal, percebemos que, por meio dele, tem-se a oportunidade de construir a própria identidade, interagir e ter suporte social e financeiro.

Em última instância, o pensamento plural e sistêmico deve refletir a necessidade de igualmente pluralizar a possibilidades verdadeiras de propiciar avanços sociais e científicos em vista da satisfação das necessidades básicas e fundamentais do ser humano.

\section{Prof. Dr. Heitor Romero Marques}

Editor

\section{REFERÊNCIAS}

LOPES, Alzira Das Mercês; MATA, Liliane Cunha Campos. Automedicação entre graduandos das áreas de saúde e exatas da faculdade ciências da vida na cidade de Sete Lagoas/MG. Revista Brasileira de Ciências da Vida, v. 5, n. 1, 2017. Disponível em: http://jornal.faculdadecienciasdavida.com.br/index.php/RBCV/article/ view/155. Acesso em: 14 jul. 2019. 
MAZZI, Regina Aparecida; MARQUES, Heitor Romero; RIPOLL, Rafael Ravina. A felicidade, o bem estar e a confiança no ambiente de trabalho. In: RIPOLL, Rafael Ravina; PESANTEZ, Luis Bayardo Tobar; BARRIOPEDRO, Estla Nuñez (Coord.). Happiness management and creativity the XXI Century - intangible capitales as a source of innovation, competitivenss and sustainable development. Granada: Editorial Comares, S. L., 2019.

NAPOLITANO, Carlo José. Limites à liberdade de expressão do pensamento: diversas perspectivas. In: CONGRESSO BRASILEIRO DE CIÊNCIAS DA COMUNICAÇÃO - INTERCOM, 40., Curitiba, PR, 4-9 set. 2017. Anais [...]. Curitiba: Universidade Positivo, 2017. Disponível em: http://portalintercom.org.br/eventos1/congressonacional/20173. Acesso em: 13 jul. 2019.

ORGANIZAÇÃO DAS NAÇÕES UNIDAS (ONU). Declaração Universal dos Direitos Humanos. Nova York: ONU, 1948.

ROMERO-RODRIGUES, Luis M.; CASTILHO-ABDUL, Bárbara. Comunicación para la motivación. Claves de la asertividad y del trabajo en equipo em las organizaciones in: RIPOLL, Rafael Ravina; PESANTEZ, Luis Bayardo Tobar; BARRIOPEDRO, Estla Nuñez (Coord.). Happiness management and creativity the XXI Century-intangible capitales as a source of innovation, competitivenss and sustainable development. Granada: Editorial Comares, 2019.

SATO, Suzenir Aguiar da Silva; ALEIXO, Andreia Duarte; OLIVEIRA, Nilza Duarte Aleixo de; Nicolas Alessandro de Souza BELETE; Devaneide de Jesus Marcilio. Gestão dos resíduos sólidos: um estudo das estratégias e políticas públicas para o desenvolvimento local sustentável do município de Pimenta Bueno/RO. In: ENCONTRO NACIONAL DE ENGENHARIA DE PRODUÇÃO- PERSPECTIVAS GLOBAIS PARA A ENGENHARIA DE PRODUÇÃO, 35., Fortaleza, CE, 13 a 16 de outubro de 2015. Anais [...]. Fortaleza: ABEPRO, 2015. Disponível em: http://www.abepro.org. br/biblioteca/TN_STO_214_269_27809.pdf/. Acesso em: 14 jul. 2019. 
